\title{
DEGRADAÇÃO DE XENOBIÓTICOS POR FUNGOS FILAMENTOSOS ISOLADOS DE AREIA FE NÓLICA(1)
}

\author{
J.H.SILVA(2) \& R.T.R. MONTEIRO(3)
}

\begin{abstract}
RESUMO
Microrganismos foram isolados de areia fenólica resultante de atividades metalúrgicas, uti lizando meio mínimo para fungos e pentaclorofenol (PCF) como única fonte de carbono. Após quatro repiques sucessivos em intervalos de 15 dias de incubação, as culturas foram plaqueadas em meio de Martin. Três gêneros de fungos foram isolados e identi ficados como Acremoni um sp., Paecilomyces sp. e Peni cillium sp. Estes foram testados para degradar os corantes índigo e RB BR (Azul Brilhante de Remazol - R) e o organoclorado PCF . A descoloração do índigo foi de $99 \%$, para Paecilomyces e Penicilli um, e de $74 \%$, para Acremonium, e a de RBBR foi de $16 \%$, para Penicillium; $14 \%$, para Acremonium, e $5 \%$, para Paeci lomyces. Usando azul de bromotimol como indicador de degradação de PCF, foram obtidos $\mathbf{2 4 \%}$ de descoloração para Acremonium; 22\%, para Penicillium, e $17 \%$, para Paeci lomyces. Utilizando cromatografia gasosa, detectou-se degradação de PCF de 69\%, para Penicillium; 65\%, para Paeci lomyces, e 40\% para Acremonium, respectivamente. Os resultados mostraram que foi possível isolar microrganismos de uma areia de fundição, altamente contami nada com fenóis, e os fungos isolados foram capazes de degradar PCF e outros xenobióticos testados.
\end{abstract}

Termos de indexação: biorremediação, seleção, pentaclorofenol, RBBR, índigo.

\section{SUMMARY: DEGRADATION OF XENOBIOTICS BY FILAMENTOUS FUNGI ISOLATED FROM PHENOLIC SANDS}

Microorganisms wereisol ated from phenolic sands resulting from metal lurgic activities, using Minimal Medium for fungi containing pentachl orophenol (PCP) as the only carbon source After four successive subcultures every 15 incubation days, the final culture was

\footnotetext{
(1) Parte da Tese de Mestrado do primeiro autor. Projeto financiado pela FUNDUNESP/RHODIA. Recebido para publicação em abril de 1999 e aprovado em junho de 2000.

(2) Mestre em Agronomia área Microbiologia Agrícola, Escola Superior de Agricultura "Luiz de Queiroz"- ESALQ. Av. Pádua Dias 11, Caixa Postal 09, CEP: 13480-900 Piracicaba (SP). Bolsista da CAPES

(3) Pesquisadora do Centro de Energia Nuclear na Agricultura - CENA/USP. Av. Centenário 303, Caixa Postal 96, CEP: 13400-970 Piracicaba (SP). E-mail: monteiro@cena.usp.br
} 
plated on Martin Medium Agar. Three different fungi were isolated and subsequently identified as Acremonium sp., Paecilomyces sp. and Penicillium sp.; which weretested for their ability to degrade: PCP, indigo dye and Remazol Brilliant Blue R (RBBR). The decolouration of indigo dye was $99 \%$ for Paecilomyces and Penicillium and $74 \%$ for Acremonium. The decol ouration of RBBR was $16 \%$ for Penicillium, $14 \%$ for Acremonium and $5 \%$ for Paecilomyces. Using bromothymol blue as indicator of PCP degradation, $24 \%$ decol ouration was obtained for Acremonium, 22\% for Penicillium and 17\% for Paecilomyces. Degradation of PCP measured by gas chromatography was $69 \%$ by Penicillium, $65 \%$ by Paecilomyces and $40 \%$ by Acremonium. Theresul ts indicated that filamentous fungi could be isolated from a highly phenol-contamined area, and that these fungi were also able to degrade PCP and other xenobiotic compounds tested.

Index terms: bioremediationm screening, RBBR, indigo, biodegradation, pentachlophenol.

\section{INTRODUÇÃO}

A descontaminação do ambiente, utilizando a habilidade natural dos organismos em mineralizar, transformar ou até mesmo combinar compostos poluentes com outras moléculas, é conhecida como biorremediação. Quando seutilizam mi crorganismos, seu isolamento e caracterização são prérequisitos importantes para mel hor conhecimento e otimização do processo.

Dentre os compostos poluentes, destacam-se os clor ofenóis que foram, ao longo da história, um dos principais compostos químicos industrializados, sendo hoje detectados em sol os, sedimentos, águas e al imentos, apresentando grande toxidez e poder de bioacumulação nos níveis tróficos superiores, além deserem recalcitrantes (Crosby, 1981; Paasavirta et al., 1985). Apesar de o pentaclorofenol (PCF) ser potente fungicida e bactericida, sua biodegradação pode ocorrer no ambiente ou em laboratório, sendo promovida por diversos grupos de microrganismos, aeróbios ou anaeróbios. Diversos fungos e bactérias que crescem com PCF como única fonte de carbono têm sido isolados (Silva, 1999).

A pré-exposição de sol os a um composto químico poluente ou a composto quimicamente semel hante pode influenciar a velocidade de degradação deste composto, pela indução de enzimas específicas dos microrganismos presentes ou pelo aumento da população degradadora (Racke, 1990). Esse processo tem sido chamado de adaptação, o qual pode ser resultado de mudanças genéticas, fisiológicas ou ecológicas da comunidade mi crobiana. A adaptação microbiana a pesticidas ébastanteevidente em solos que receberam repetidas aplicações de pesticidas (Racke, 1990). Tal adaptaçãofoi também comprovada para compostos fenól i cos em sol os contaminados por produtos químicos industriais, onde uma linhagem de Penicillium foi isolada, podendo influir na velocidade de remoção desses contaminantes por meio da indução de enzimas específicas, do aumento de certas comunidades ou mesmo pela mudança de populações microbianas ali presentes (H ofrichter et al., 1993).

Dentre os métodos de triagem para encontrar microrganismos com capacidade de degradar compostos de interesse, o método do enriquecimento éum dos mais recomendados (Cook et al., 1983; M elo \& Azevedo, 1997), o qual, usualmente, utiliza o compostoa ser degradado como fonte de um nutriente essencial em meio decultura definido. Para isolamento de culturas degradadoras de organoclorados, podemse utilizar também indicadores ácido-base, comoazul de bromotimol, eosina ou azul de metileno, os quais, quando incorporados ao meio, formam halo ou mudança de cor decorrente da liberação de íons cloreto.

A utilização de corantes poliméricos (por ex., Azul Brilhante de Remazol -R (RBBR)) como método de triagem, seja para identificar atividade lignolítica, seja para avaliar a capacidade em degradar xenobióticos, oferece uma série de vantagens, pois permite o desenvolvimento de métodos espectrofotométricos simples, rápidos equantitativos. Além disso, apresentam baixa toxidez para os microrganismos e sua natureza polimérica assegura que sua degradação, pelo menos nas etapas iniciais, ocorra extracelularmente (Glenn \& Gold, 1983).

O presenteestudo tevecomo objetivos isol ar fungos filamentosos de uma área altamente contaminada com compostos fenólicos, por meio do método de enriquecimento, e testar a capacidade desses microrganismos em degradar um composto derivado do fenol (PCF) e outros altamente complexos e poliméricos, como os corantes RBBR eíndigo.

\section{MATERIAL E MÉTODOS}

Amostras de $3 \mathrm{~kg}$ de areia fenólica residuária de metalúrgicas que utilizam resinas fenólicas no 
processo de fundição foram coletadas na região de Campinas (SP), próximo ao distrito de Souzas, em uma área de descarte de resíduos. Amostras foram secas ao ar, o suficiente para serem peneiradas em malha de $2 \mathrm{~mm}$, sendo então homogeneizadas em sacos de polietileno. O teor de umidade foi determinado em $10 \mathrm{~g}$, em três repetições, por secagem em estufa (105॰C, $24 \mathrm{~h})$. O número de microrganismos foi determinado pela técnica de diluição e plaqueamento em meios específicos a fungos (Martin, 1950), actinomicetos (peptona) e bactérias (Nutriente agar).

Nos diversos testes de degradação, foram utilizados: meio mínimo (MM), conforme Pontecorvo et al. (1953); MM modificado, acrescentando nutriente e reduzindo a glicose a 0,2 \%; MMB: acrescentaram-se $18 \mathrm{~g}$ de bagaço de cana triturado; MMC: acrescentou-se o corante têxtil índigo; MMR: acrescentou-se o corante RBBR (Sigma) a 0,02\%; MMI: acrescentaram-se extrato delevedura a $0,05 \%$, PCF a $4 \mathrm{mg} \mathrm{L}^{-1}$ eazul de bromotimol a 0,02\%; MMP: acrescentaram-se extrato delevedura a 0,05\% ePCF em quantidades equivalentes à concentração final desejada no meio, conformeStanlake\& Finn (1982). Foram preparados $10 \mathrm{~mL}$ de uma solução estoque, utilizando 0,4 g de PCF : 2, 3, 4, 5, 6 -pentacl orofenol (Merck - 98\% de pureza) em NaOH $\left(0,2 \mathrm{~mol} \mathrm{~L}^{-1}\right)$.

Para o isolamento de fungos, $100 \mathrm{~g}$ de areiafenólica seca foram col ocados em frasco E rlenmeyer com capacidade de $2 \mathrm{~L}$, contendo $900 \mathrm{~mL}$ de soluç̧ão salina $(0,89 \% \mathrm{v} / \mathrm{v})$. Agitou-se mecanicamente por $10 \mathrm{~min}$. Após repouso, durante $15 \mathrm{~min}$, fez-se uma filtragem, desprezando-se os $200 \mathrm{~mL}$ iniciais (IBAMA, 1990). O filtrado foi centrifugado (centrífuga Bekman J 2-HS) a $4.000 \mathrm{G}$ e $8^{\circ} \mathrm{C}$ por $15 \mathrm{~min}$, sendo o precipitado lavado com solução salina e ressuspendido em $11 \mathrm{~mL}$ da mesma solução e novamente centrifugado e ressuspendido. Desta suspensão, foi retirado $1 \mathrm{~mL}$, para inocular frascos Erlenmeyer de $125 \mathrm{~mL}$ (tréplica) com $50 \mathrm{~mL}$ de meio MMP com PCF a 2 mg L-1. Os frascos foram incubados em agitador (New Brunswick Sc. Co. Inc.) a $150 \mathrm{rpm}$, no escuro, a $29^{\circ} \mathrm{C}$. Foram realizados quatro repiques sucessivos, em intervalo de 15 dias, de $1 \mathrm{~mL}$ para frascos novos que continham meio MMP com PCF (2 mg L-1). A seguir, após cada 15 dias deincubação, a partir do último repique, aumentousea concentração de PCF até $80 \mathrm{mg} \mathrm{L-1}$, observandose crescimento nas concentrações de 4,20 e 40 mg L-1. Transferiu-se 0,1 mL doúltimorepique para placas de Petri com meio de Martin que continha $4 \mathrm{mg} \mathrm{L-1}$ dePCF, para oisolamento dos fungos, sendo as placas incubadas em estufa incubadora (BOD) a $29^{\circ} \mathrm{C}$.

O inóculo para a manutenção das culturas e real ização dos testes de degradação constituiu-se de discos contendo micélio, esporos e meio de cultura, retirados com um cortador de metal de $5 \mathrm{~mm}$ de diâmetro das bordas das colônias desenvolvidas em meio de Martin, durante 7 dias.
A biomassa fúngica formada foi determinada por meio da filtragem da cultura em sistema de vácuo, utilizando papel defiltro (Whatman no 1 ) previamente pesado. $O$ filtrado e o filtro foram secos por $2 \mathrm{~h}$ em estufa a $105^{\circ} \mathrm{C}$.

Para o teste de degradação do corante índigo, frascos Erlenmeyer de $125 \mathrm{~mL}$ com $25 \mathrm{~mL}$ de meio MMC foram inoculados em tréplica e incubados juntamente com os controles, não inoculados, em agitador com temperatura controlada a $150 \mathrm{rpm}$ e $29^{\circ} \mathrm{C}$, no escuro. Após sete dias de incubação, foram real izadas medidas de biomassa e descol oração por espectrofotometria a $580 \mathrm{~nm}$, como recomendado por Balan (1998).

A degradação do corante polimérico RBBR foi testada, utilizando inóculos preparados em MMB que continham bagaço decana como fonte de carbono (lignina e hemicelulose), para ativar o sistema lignolítico. Frascos Erlenmeyer de $125 \mathrm{~mL}$ com $25 \mathrm{~mL}$ de meio MMR foram incubados, em tréplica, em agitador a $150 \mathrm{rpm}$ e $29^{\circ} \mathrm{C}$, no escuro. Após sete dias de incubação, foram efetuadas medidas de bi omassa e de absorvância a 595 nm (Glenn \& Gold, 1983).

A degradação do PCF foi avaliada por dois métodos: pel o método descrito por Saber \& Crawford (1985), utilizando azul de bromotimol como indicador de $\mathrm{pH}$, e por cromatografia gasosa, medindo sua dissipação. O primeiro baseia-se na mudança de col oração do meio de azul esverdeado para amarelo devidoà liberação de íons cl oreto do anel fenólico do PCF. Frascos Erlenmeyer de $125 \mathrm{~mL}$ com $25 \mathrm{~mL}$ de meio MMI com $5 \mathrm{mg} \mathrm{L}^{-1}$ de PCF foram inoculadose, em seguida, vedados com filme plástico, evitandose, assim, a perda de compostos voláteis. O mesmo foi feito para os controles, sem inocúlo. A pós sete dias de incubação a $29^{\circ} \mathrm{C}$, foram determinados a al teração da cor (visual); pH; absorvância por espectrofotometria (318 $\mathrm{nm}$ ) e biomassa formada.

Para o outro método de degradação do PCF, utilizou-se $1 \mathrm{~mL}$ de cultura crescida em meio de Martin com 4 mg L-1 de PCF como inóculo de frascos Erlenmeyer de $125 \mathrm{~mL}$ (tréplica), que continham $25 \mathrm{~mL}$ de meio MMP com $4 \mathrm{mg} \mathrm{L-1}$ de PCF. Estes foram incubados em agitador com temperatura controlada, a 150 rpme $29^{\circ} \mathrm{C}$, no escuro. Após 20 dias, adicionaram-se $40 \mu \mathrm{L}$ de $\mathrm{H}_{2} \mathrm{SO}_{4}$ concentrado para estacionar o crescimento elisar as células. A extração do PCF foi realizada pelo método em fase sólida (Liska et al., 1989), utilizando col unas C18 (Alltech, USA) de $6 \mathrm{~mL}$ preenchidas com $500 \mathrm{mg}$ de adsorvente. $O$ extrato foi previamente derivatizado por metilação (Airoldi, 1997). A determinação do PCF foi realizada no Instituto de Química de São Carlos/ USP, em cromatógrafo a gás Hewlett Packard 5890 sériell, equi pado com detector de captura deel étrons (ECD/63Ni) einjetor "split". As condições de operação foram: coluna SP2330 (90\% bis-cianopropil / 10\% fenil cianopropil polissiloxano), com dimensões de 
$30 \mathrm{~m} \times 0,25 \mathrm{~mm} \times 0,20 \mu \mathrm{m}$; temperatura do injetor: $280^{\circ} \mathrm{C}$; temperatura do detector: $300^{\circ} \mathrm{C}$; gás dearraste: $\mathrm{H}_{2}$, $1 \mathrm{~mL}$ min-1; programação de temperatura: 160$230^{\circ} \mathrm{C}\left(1^{\circ} \mathrm{C} \mathrm{min-1)}\right.$; razão de "split" 1:15; volume injetado: $1 \mu \mathrm{L}$.

\section{RESULTADOSE DISCUSSÃO}

Microrganismos do resíduo areia fenólica revelaram conter em termos de unidade formadora de colônia por grama de solo: 1,5 x 108, para bactérias; 5 × 102, para actnomicetos, e 7 × 102, para fungos, sendo, portanto, um resíduo rico em microrganismos resistentes a compostos fenólicos.

Os quatro repiques sucessivos em meio MM contendo $4 \mathrm{mg} \mathrm{L}^{-1}$ de PCF como única fonte de carbono permitiram o isolamento de três linhagens de fungos. Posteriormente, os isolados foram identificados, no I nstituto de Botânica deSão Paulo, como sendo: Acremonium sp, Paecilomyces sp e Penicilliumsp.

Fungos filamentosos, pertencentes aos gêneros Mucor, Paecilomyces, Demamatium, Monila, Homodendrum, Geotrichum e Alternaria com capacidade de degradar fenóis, foram também isolados de areia fenólica de fundição por Teixeira (1993).

Pesquisas com degradação de poluentes industriais indicaram que o crescimento dos microrganismos degradadores em condições limitantes de nutrientes orgânicos modula a resposta adaptativa (Racke, 1990). Dessa forma, os testes de degradação de compostos xenobióticos foram realizados com redução de $10 \%$ da fonte de carbono do meio.

Os fungos Paecilomyces sp. e Penicillium sp. conseguiram descolorir, significativamente, o corante índigo (99\% com relação ao controle). Acremonium sp. também reduziu significativamente o corante (74\%) (Quadro 1).
Apesar de RBBR apresentar uma estrutura molecular complexa, os fungos mostraram-se capazes de degradar (descolorir) este corante (Quadro 1). Paecilomyces foi o que apresentou a menor percentagem $(4,75 \%)$ de descol oração, seguido por Acremonium (14\%) e Penicillium (16\%).

Comparando os resultados de bi omassa formada para os três fungos, percebe-se que não há toxidez dos corantes índigo ou RBBR. Para quea degradação ocorra, além de apresentar uma quantidade de biomassa satisfatória, é necessário que o fungo apresente um sistema enzimático capaz de degradar o composto. O corante RBBR é também utilizado para quantificar enzimas ligninolíticas (Glenn \& Gold; 1983) e poluentes orgânicos (Field et al., 1993). A degradação desses dois corantes, embora pertençam a classes diferentes (antraquinona e índigo), ocorre por meio das enzimas fenol-oxidases (peroxidases, tirosinases elacases). Essas enzimas são, em sua maioria, extracelulares e produzidas durante o metabolismo secundário, sendo induzidas pelo substrato (Glenn \& Gold, 1983). Hoje, sabe-se que as lacases são as principais enzimas responsáveis pela degradação do corante índigo (Wong \& Yu, 1999).

Pasti-Grigsby et al. (1992) relataram que não só a variação na complexidade da estrutura de vários corantes e a sua concentração influenciam a capacidade de degradação, mas também quealguns corantes podem ser adsorvidos à massa micelial. Os resultados de estudos com basidiomicetos por Dietrich et al. (1995) mostraram queo primeiro passo para a biodegradação somente ocorre quando substrato e sítios reativos entram em contato, sendo o corante primeiramente adsorvido às hifas para depois ocorrer a degradação.

No presente estudo, parte dos corantes foi prontamente retirada do meio de cultura, ficando aderida ao micélio. Então, foi realizado um teste, utilizando o corante no meio não inoculado e com inóculo morto por esterilização em autoclave. Em

Quadro 1. Absorvância, percentagem de descoloração dos corantes índigo e RBBR em MMC e MMR, respectivamente, e biomassa ( \pm desvio-padrão), após sete dias de incubação a $29^{\circ} \mathrm{C}$ sob agitação

\begin{tabular}{lcccccc}
\hline Fungo & Absorvância & Descoloração & Biomassa & Absorvância & Descoloração & Biomassa \\
\hline & $580 \mathrm{~nm}$ & (\%) Índigo & $\mathrm{mg}$ & $595 \mathrm{~nm}$ & $(\%) \mathrm{RBBR}$ & $\mathrm{mg}$ \\
Paecilomyces sp & $0,031 \mathrm{a}$ & 99,70 & $36,2 \pm 0,9$ & $1,751 \mathrm{~b}$ & 4,75 & $33,9 \pm 0,4$ \\
Penicillium sp & $0,048 \mathrm{a}$ & 99,11 & $44,9 \pm 0,5$ & $1,539 \mathrm{a}$ & 16,28 & $35,7 \pm 0,6$ \\
Acremonium sp & $0,750 \mathrm{~b}$ & 74,52 & $36,8 \pm 0,2$ & $1,583 \mathrm{a}$ & 13,88 & $35,8 \pm 0,7$ \\
CT(1) & 3,010 c & - & - & $2,060 \mathrm{c}$ & - & - \\
\hline
\end{tabular}

Os valores representam a média de três repetições. Valores de absorvância com mesmo expoente não diferem entre si pelo teste de Tuckey $(P<0,05)$.

(1) Meio sem inóculo, diluído 10x para leitura. 
ambos os casos, o corante permaneceu no meio, mostrando que o desaparecimento não foi devido somente à adsorção ao mi célio, mas também à ação metabólica dos fungos.

Por indicação doazul debromotimol, os resultados evidenciarama potencialidade dos três fungos isolados em degradar o PCF, uma vez quetodos alteraram a cor do meio deazul esverdeado para amarelo, considerando a liberação de íons $\mathrm{Cl}^{-}$no meio (Quadro 2).

Como estes fungos foram isolados em meio que continha PCF como única fonte de carbono, já eram esperados um bom crescimento e a presença de degradação, sendo, portanto, esta relacionada coma biomassa formada.

Utilizando a cromatografia gasosa (CG), calculouse a concentração do controle, comparando as áreas do pico apresentadas no controle e no padrão. $O$ padrão apresentou para $5 \mathrm{mg} \mathrm{L}^{-1}$ um pico com área 667.823 , equivalente a $100 \%$. Os valores para os tratamentos foram cal culados pela comparação das áreas obtidas em cada pico para cada tratamento, com a área 585.143 equivalente a $4,38 \mathrm{mg} \mathrm{L}^{-1}$ do controle correspondendo a 100\% (Quadro 3).
Penicillium apresentou percentagem de degradação do PCF por volta de $70 \%$, seguido por Paecilomyces (64\%), não diferindo estas taxas estatisticamente. J á ofungo Acremonium apresentou a menor percentagem (40\%) de degradação (Quadro 3), tendo sido todos os tratamentos significativamente diferentes em relação ao controle. Uma vez que PCF foi utilizado como fonte de carbono para obtenção de energia e biomassa, a capacidade dos fungos de degradá-lo foi demonstrada. Os dois testes de degradação de PCF não foram comparáveis, visto ser o azul de bromotimol qualitativo e CG quantitativo. Houve também diferença entre a composição do meio de cultura e tempo de incubação.

\section{CONCLUSÃO}

1. É possível isolar fungos filamentosos de areias fenólicas, com potencial em degradar compostos xenobióticos, comoPCF eos corantes índigoeRBBR.

Quadro 2. Descoloração do PCF por indicação do azul de bromoti mol e biomassa ( \pm desvio-padrão), após sete dias de incubação a $30^{\circ} \mathrm{C}$

\begin{tabular}{lccccc}
\hline Fungo & Cor & pH & Absorvância & Descoloração & Biomassa \\
\hline & & & $318 \mathrm{~nm}$ & $\%$ & $\mathrm{mg}$ \\
Paecilomyces sp. & + & 6,8 & 1,226 & 16,72 & $35,76( \pm 0,66)$ \\
Penicillium sp. & + & 6,7 & 1,145 & 22,06 & $43,50( \pm 0,4)$ \\
Acremonium sp. & + & 6,8 & 1,113 & 24,32 & $54,98( \pm 0,86)$ \\
CT & $-11)$ & 7,0 & 1,430 & - & \\
\hline
\end{tabular}

(1) meio sem inóculo, diluído 10x para leitura. Os valores representam a média de três repetições; (+) amarelo; (-) azul.

Quadro 3. Média das áreas dos picos formados; percentagem de degradação do PCF e concentração de PCF restante no meio, após 20 dias de incubação sob agitação, no escuro a $30^{\circ} \mathrm{C}$

\begin{tabular}{lccc}
\hline \multicolumn{1}{c}{ Fungo } & Área & Degradação & PCF \\
\hline & & $\%$ & $\mathrm{mg} \mathrm{L}^{-1}$ \\
Paecilomyces sp. & $202.932 \mathrm{a}$ & 64,4 & 1,56 \\
Penicillium sp. & 179.895 a & 69,2 & 1,35 \\
Acremonium sp. & $349.188 \mathrm{~b}$ & 40,4 & 2,61 \\
CT(1) & $585.143 \mathrm{c}$ & - & 4,38 \\
Padrão PCF & 667.823 & - & 5,00
\end{tabular}

(1) Meio sem inóculo. Áreas com mesmo expoente não diferem estatisticamente $(P<0,05)$ pelo teste $t$.

\section{LITE RATURA CITADA}

AIROLDI, F.P.S. Determinação de pentaclorofenol e hexaclorobenzeno em solo contaminado por resíduos industriais. São Carlos, Instituto de Química de São Carlos, Universidade de São Paulo, 1997. 70p. (Tese de Mestrado)

BALAN, D.S.L. Biodegradação e toxicidade de efluentes têxteis: coranteíndigo. Rio Claro, Universidade Estadual Paulista, 1998. 130p. (Tese de Doutorado)

COOK, A.M.; GRORSENBACHER, H. \& HUTTER, R. I solation and cultivation of microbes with biodegradative potential. Experientia, 39:1191-1198, 1983.

CROSBY, D.G. Environmental chemistry of pentachlorophenol. Pure Appl. Chem., 53:1051-1080, 1981. 
DIETRICH, D.; HICKEY, W.J . \& LAMAR, R. Degradation of 4,4'dichlorobiphenyl, 3,3',4,4'-tetrachlorobi phenyl, and 2,2',4,4',5,5'-hexachlorobiphenyl by the white rot fungus Phanerochaete chrysosporium. Appl. Environ. Microb., 61:3904-3909, 1995.

FIELD, J .A.; DEJ ONG, E.; FEIJ OOCOSTA, G. \& DEBONT, J.A.M. Screening for ligninolytic fungi applicable to the biodegradation of xenobiotics. Trends Biotechnol., 11:4449, 1993.

GLENN,J .K. \& GOLD, M.H. Decolorization of several dyes by a lignin degrading basidiomycete Phanerochaete Chrysosporium. Appl. Environ. Microb., 45:1741-1747, 1983.

HOFRICHTER, M.; GUNTHER, T. \& FRITSCHE, W. Metabolism of phenol, choro- and nitrophenols by the Penicillium strain Bi 712 isolated from a contamined soil. Biodegradation, 3:415-421, 1993.

INSTITUTO BRASILEIRO DO MEIO AMBIENTE E DOS RECURSOS NATURAIS RENOVÁVEIS - IBAMA. Manual de testes para avaliação de ecotoxicidade de agentes químicos. 2.ed. Brasília, 1990. 351p.

LISKA, I.; KRUPICIK, J . \& LECLERQ, P.A. The use of solid sorbents for direct accumulation of organic-compounds from water matrices - A review of solid-phase extraction techniques. J . High Resol. Chromatog., 12:577-590, 1989.

MARTIN, J .P. Use of acids rose-bengall and streptomicin in the plate method for estimating soil fungi. Soil Sci., 134:215232, 1950.

MELO, I.S. \& AZEVEDO, J.L. Como isolar microrganismos degradadores de moléculas xenobióticas. In: MELO, I.S. \& AZEVEDO, J .L., eds. Microbiologia ambiental. J aguariúna, Empresa Brasileira de Pesquisa Agropecuária, 1997. p.167183.
PAASIVIRTA, J .; HEINOLA, K. \& HUMPPI, T. Polychlorinated phenols, guaiacols, and catechols in environment. Chemosphere, 14:469-491, 1985.

PASTI-GRIGSBY, M.B.; PASZCZYNSKI, S.; CRAWFORD, D.L. \& CRAWFORD, R.L. Influence of aromatic substitution patterns an azo dye degradability by Streptomyces spp. and Phanerochaete chrysosporium. Appl. Environ. Microb., 58:3605-3613, 1992

PONTECORVO, G.; ROPER, J.A.; HERMONS, L.M.; MCDONALD, K.D. \& BUFTON, A.W.J. The genetics of Aspergillus nidulans. Adv. Genet., 5:141-238, 1953.

RACKE, D.K.. I mplications of enhanced biodegradation for the use and study of pesticides in the soil environment. In: RACKE, D. K. \& COATS, J .R., eds. Enhanced biodegradation of pesticides in the environment. Washington, DC, ACS, 1990. p.269-282. (ACS Symposium Series, 426)

SABER, D.L. \& CRAWFORD, R.L. I solation and characterization of Flavobacterium strains that degrade pentachlorophenol. Appl. Environ. Microbiol., 50:1512-1518, 1985.

SI LVA, J .H. I sol amento e caracterização de fungos filamentosos capazes de degradar pentaclorofenol (PCF). Piracicaba, Escola Superior de Agricultura Luiz de Queiroz. 1999. 70p. (Tese de Mestrado)

STANLAKE, G.J . \& FINN, R.K. I solation and characterization of a pentachorophenol-degrading bacterium. Appl. Environ. Microbiol., 44:1421-1427, 1982.

TEIXEIRA, C.E. Ensaios de tratabilidade de resíduo sólido industrial - areia fenólica: isolamento, identificação esel eção de fungos filamentosos. Campinas, Universidade de Campinas, 1993. 108p. (Tese de Mestrado)

WONG, Y . \& YU, J . Laccase-catalysed decol orization of synthetic dyes. Water Res., 33:3512-3520, 1999. 